\title{
Epidemiology of enteric disease in C-EnterNet's pilot site - Waterloo region, Ontario, 1990 to 2004
}

\author{
Victoria A Keegan $\mathrm{MSc}^{1,2}$, Shannon E Majowicz $\mathrm{PhD}^{1,2}$, David L Pearl DVM PhD ${ }^{1}$, Barbara J Marshall MES CPHI(C) ${ }^{2}$, \\ Nancy Sittler BSc CPHI(C) ${ }^{3,4}$, Lewinda Knowles $\mathrm{MHSc}^{4}$, Jeffery B Wilson DVSc $\mathrm{PhD}^{1,2}$
}

\begin{abstract}
VA Keegan, SE Majowicz, DL Pearl, et al. Epidemiology of enteric disease in C-EnterNet's pilot site - Waterloo region, Ontario, 1990 to 2004. Can J Infect Dis Med Microbiol 2009;20(3):79-87.
\end{abstract}

OBJECTIVE: The objective of the present study was to describe the epidemiology of reportable enteric illness in Ontario's Waterloo region, including comparing calculated incidence rates with published rates, and adjusting for under-reporting to determine the number of community cases, where published data were available.

METHODS: Descriptive analyses were performed on reportable disease data for 13 enteric diseases collected in the Waterloo region from 1990 to 2004. Poisson and negative binomial regression analyses were used to investigate differences in incidence rates among age, sex, the 15 years of data and seasons. Disease-specific incidence rates were calculated and compared with the literature, where possible. Under-reporting ratios from the literature were applied to estimate the number of cases of campylobacteriosis, nontyphoidal salmonellosis and verotoxigenic Escherichia coli infection at the community level.

RESULTS: Over the study period, the average annual age- and sexadjusted incidence rates per 100,000 population were highest for campylobacteriosis (49.69 cases), followed by giardiasis (31.87 cases) and nontyphoidal salmonellosis (25.97 cases). The incidence of most enteric illnesses peaked in the summer. The highest incidence occurred in young children, followed by adults in their 20s. Diarrhea (85.4\%) was the most frequently reported symptom, food $(57.4 \%)$ was the most commonly reported probable source, and home $(41.7 \%)$ and travel $(37.0 \%)$ were the two most frequently reported risk settings.

CONCLUSIONS: Enteric illness was a significant health burden in the Waterloo region from 1990 to 2004. Because reportable disease data are subject to under-reporting, it is likely that the true burden is greater than estimated in the present study.

Key Words: Campylobacter, Canada, Gastroenteritis, Giardia, Ontario, Population surveillance, Salmonella

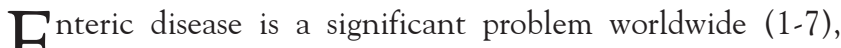
$\mathrm{C}_{\text {with an estimated } 76 \text { million cases annually in the United }}$ States (2) and rates many times higher in developing countries, particularly affecting children (5). The burden of enteric disease in Canada is considerable (8-16), with an average of 313 community cases of infectious gastroenteritis for each case reported to the provincial level (9). Efforts to investigate and mitigate the burden of enteric disease involve syndromic surveillance $(17,18)$, laboratory surveillance (19), outbreak investigation $(20,21)$ and disease notification (22). In Canada, surveillance for enteric diseases is a provincial and territorial

\section{Épidémiologie de la maladie entérique dans un centre pilote du projet C-EnterNet, région de Waterloo, Ontario, 1990 à 2004}

OBJECTIF : L'objectif de la présente étude était de décrire l'épidémiologie de la maladie entérique à déclaration obligatoire dans la région de Waterloo, en Ontario, incluant une comparaison entre les taux d'incidence calculés et les taux publiés, après ajustement pour tenir compte des cas non déclarés, de manière à évaluer le nombre de cas extrahospitaliers, là où des données publiées étaient disponibles.

MÉTHODES : Les auteurs ont procédé à des analyses descriptives des données relatives à 13 maladies entériques à déclaration obligatoire dans la région de Waterloo, entre 1990 et 2004. Ils ont utilisé des analyses de Poisson et de régression binomiale négative pour relever les différences de taux d'incidence selon l'âge, le sexe, les 15 années de collecte de données et les saisons. Les taux d'incidence spécifiques à chaque maladie ont été calculés et comparés à ceux de la littérature publiée, le cas échéant. Les taux de sous-déclaration présentés dans la littérature ont été appliqués pour estimer le nombre de cas extrahospitaliers de campylobactériose, de salmonellose non typhö̈dique et d'infection à Escherichia coli vérotoxigène.

RÉSULTATS : Au cours de la période de l'étude, les taux d'incidence annuels moyens ajustés selon l'âge et le sexe par 100000 de population ont été plus élevés pour la campylobactériose (49,69 cas), suivis de la giardiose ( 31,87 cas) et de la salmonellose non typhoïdique (25,97 cas). L'incidence de la plupart des maladies entériques a culminé durant l'été, la plus élevée ayant été observée chez les jeunes enfants, suivis des adultes dans la vingtaine. La diarrhée $(85,4 \%)$ a été le symptôme le plus souvent signalé. Les aliments $(57,4 \%)$ ont été la source probable la plus souvent rapportée et le domicile $(41,7 \%)$ et les déplacements $(37,0 \%)$ ont été les deux contextes de risque les plus fréquemment mentionnés.

CONCLUSION : La maladie entérique s'est révélée être un fardeau significatif sur le plan de la santé dans la région de Waterloo entre 1990 et 2004. Étant donné que les données sur les maladies à déclaration obligatoire sont parfois incomplètes, il est probable que le fardeau réel soit encore plus lourd que ne l'estime la présente étude.

responsibility, with diseases made notifiable via provincial or territorial statutes. In Ontario, laboratory-confirmed cases of notifiable enteric diseases are reported to local health units that investigate these illnesses and report details to the Ontario Ministry of Health and Long-Term Care.

Recently, the Public Health Agency of Canada facilitated the creation of C-EnterNet, a multistakeholder initiative designed to reduce the burden of enteric disease via comprehensive sentinel site surveillance implemented through local public health units. C-EnterNet's sentinel site approach is designed to complement broader provincial and national passive

\footnotetext{
${ }^{1}$ Department of Population Medicine, University of Guelph; ${ }^{2}$ Centre for Foodborne, Environmental and Zoonotic Infectious Diseases; ${ }^{3}$ Laboratory for Foodborne Zoonoses, Public Health Agency of Canada, Guelph; ${ }^{4}$ Region of Waterloo Public Health Department, Regional Municipality of Waterloo, Waterloo, Ontario

Correspondence and reprints: Ms Victoria Keegan, Centre for Foodborne, Environmental and Zoonotic Infectious Diseases, Public Health Agency of Canada, 255 Woodlawn Road West, Unit 120, Guelph, Ontario N1H 8J1. Telephone 519-826-2173, fax 519-826-2244, e-mail victoria_keegan@phac-aspc.gc.ca
}

Received for publication April 15, 2008. Accepted September 4, 2008 
TABLE 1

Number of cases and age- and sex-adjusted incidence rates* per 100,000 population for 13 reportable enteric illnesses $(n=8326)$ in Ontario's Waterloo region, 1990 to 2004

\begin{tabular}{|c|c|c|c|c|c|c|c|}
\hline \multirow[b]{2}{*}{ Disease } & \multicolumn{2}{|c|}{ Total cases } & \multicolumn{5}{|c|}{$\begin{array}{l}\text { Annual age- and sex-adjusted } \\
\text { incidence rates per } 100,000 \text { population }\end{array}$} \\
\hline & $\mathbf{n}$ & $\%$ & Maximum & Year I & Minimum & Year & Average \\
\hline Campylobacteriosis & 3167 & 38.04 & 75.00 & 1993 & 34.17 & 1998 & 49.69 \\
\hline Giardiasis & 2038 & 24.48 & 70.66 & 1990 & 11.59 & 2004 & 31.87 \\
\hline $\begin{array}{l}\text { Nontyphoidal } \\
\text { salmonellosis }\end{array}$ & 1660 & 19.94 & 37.54 & 1990 & 16.17 & 2003 & 25.97 \\
\hline VTEC infection & 376 & 4.52 & 9.60 & 1995 & 2.72 & 2004 & 5.86 \\
\hline Amebiasis & 348 & 4.18 & 7.95 & 1991 & 2.30 & 2002 & 5.35 \\
\hline Yersiniosis & 203 & 2.44 & 5.93 & 1996 & 0.49 & 2000 & 3.11 \\
\hline Hepatitis A infection & 182 & 2.19 & 11.30 & 1991 & 0.21 & 2002 & 2.72 \\
\hline Shigellosis & 176 & 2.11 & 4.61 & 1991 & 0.73 & 2001 & 2.83 \\
\hline Cryptosporidiosis $^{\dagger}$ & 118 & 1.42 & 4.71 & 1997 & 1.84 & 1998 & 2.98 \\
\hline Typhoid fever & 27 & 0.32 & 1.18 & 1995 & 0.00 & $N / A^{\ddagger}$ & 0.36 \\
\hline Listeriosis & 12 & 0.14 & 0.91 & 2001 & 0.00 & $N / A^{\S}$ & 0.19 \\
\hline Cyclosporiasis $\llbracket$ & 10 & 0.12 & 1.49 & 2004 & 0.21 & 2003 & 0.7 \\
\hline Paratyphoid fever & 9 & 0.11 & 0.29 & 1992 & 0.00 & $N / A^{* *}$ & 0.12 \\
\hline
\end{tabular}

${ }^{*}$ Rates are standardized to the 1991 Canadian population; ${ }^{\dagger}$ Reporting began in 1996; ${ }^{\ddagger}$ No cases of typhoid fever reported in 1991,1994, 2000 and 2002; §No cases of listeriosis reported in 1990,1993,1995 to 1996,1999 to 2000 and 2003 to 2004; "Reporting began in 2000 (no cases were reported in the region of Waterloo until 2002); **No cases of paratyphoid fever reported from 1990 to 1991, 1993, 1994, 1997, and 2000 to 2001. N/A Not applicable; VTEC Verotoxigenic Escherichia coli

surveillance programs by providing more in-depth information than is feasible to collect at the provincial or national level. C-EnterNet's pilot sentinel site is Ontario's Waterloo region, where surveillance began in June 2005. To provide context for the interpretation of sentinel surveillance data, it is necessary to evaluate historical data on the epidemiology of enteric illness within the sentinel site. Therefore, the objectives of the present study were to describe the epidemiology of reportable enteric illness in the Waterloo region from 1990 to 2004, by person, place and time; to compare disease-specific incidence rates calculated in the present study with published incidence rates for the province of Ontario, where available; and to estimate the actual number of cases by adjusting for under-reporting, where possible.

\section{METHODS}

Located in southern Ontario, the Waterloo region is composed of three urban municipalities (Kitchener, Cambridge and Waterloo) and four rural townships (North Dumfries, Wellesley, Wilmot and Woolwich). It is home to three postsecondary institutions and a closed religious community. Over the study period, the population increased from nearly 400,000 residents (1990) to close to 500,000 (2004).

The data used in the present study were obtained from the region of Waterloo Public Health Department, and represented all cases of 13 reportable enteric illnesses (Table 1) captured within the Reportable Disease Information System between January 1, 1990, and December 31, 2004. Botulism, cholera and trichinosis were omitted from the present analysis because there were no cases in the Waterloo region during the study period. Outbreak cases were included in the analysis because the objective was to describe the overall epidemiology of illness in the study area.
TABLE 2

Percentage of missing or unspecified data, by variable, for 13 reportable enteric illnesses $(n=8326)$ in Ontario's Waterloo region, 1990 to 2004

\begin{tabular}{|c|c|c|c|}
\hline Variable & $\begin{array}{l}\text { Number } \\
\text { missing }\end{array}$ & $\begin{array}{c}\text { Number } \\
\text { unspecified* }\end{array}$ & $\begin{array}{c}\text { Percentage missing } \\
\text { or unspecified* }\end{array}$ \\
\hline Age & 67 & 0 & 0.8 \\
\hline Sex & 52 & 3 & 0.7 \\
\hline Disease & 0 & 0 & 0.0 \\
\hline Symptoms $^{\dagger}$ & 991 & 641 & 19.6 \\
\hline Probable source ${ }^{\ddagger}$ & 433 & 5731 & 74.0 \\
\hline Risk setting ${ }^{\ddagger}$ & 839 & 3253 & 49.1 \\
\hline Species/serotype & 736 & 835 & 18.9 \\
\hline Hospitalized & 1975 & 232 & 26.5 \\
\hline Deceased & 4032 & 477 & 54.1 \\
\hline Cause of death ${ }^{\S}$ & 9 & 7 & 64.0 \\
\hline Outbreak associated & 241 & 723 & 11.6 \\
\hline Episode date & 0 & 0 & 0.0 \\
\hline Urban/rural status & 252 & 0 & 3.0 \\
\hline Travel $^{\dagger}$ & 8233 & 0 & 98.9 \\
\hline
\end{tabular}

*Unspecified values were any values that were 'unspecified', 'unknown', 'other' or that were implausible; ' Maximum of five values allowed; 'Determined by the Public Health Investigator based on interview with the patient (only one value allowed for each variable); ${ }^{\varsigma_{n}}=$ total of 25 deaths

The variables included in the present analysis, and the proportion missing or unspecified per variable are shown in Table 2. Unspecified values were any values that were 'unspecified', 'unknown', 'other' or that were implausible. Variables within records were cross-checked to identify implausible values, and these were corrected where possible. The variable episode date (defined as the date of symptom onset) was used to derive the year, month and season that the illness occurred. The variable seasons were categorized as winter (January, February and March), spring (April, May and June), summer (July, August and September) and fall (October, November and December).

Descriptive analyses were performed using Intercooled Stata 8 (Stata Corporation, USA) and Microsoft Excel 2000 (Microsoft Corporation, USA). Age- and sex-adjusted annual incidence rates were calculated for each disease using direct standardization (23), with the 1991 Canadian population as the referent population. Age-adjusted annual incidence rates for men and women were also calculated. Two-sided Fisher's exact tests were used to compare the disease-specific proportion of urban and rural cases with the distribution of urban and rural residents in the Waterloo region, based on census data.

Regression analyses were conducted using four separate main effects models: for enteric illness overall (all 13 diseases), campylobacteriosis, giardiasis and salmonellosis (defined in the present study as nontyphoidal salmonellosis). A total of 78 cases of enteric illness, including 15 cases of campylobacteriosis, 16 cases of giardiasis and 11 cases of salmonellosis were excluded from regression modelling because they were missing data on sex or age. Ten-year age categories were used for the regression analyses, with the exception of children zero to four years of age and those five to nine years of age, which were kept separate due to their biological significance. In addition, cases of adults 70 years of age and older were combined into one category due to the small number of cases. The predictor variables - sex, age (as categorized above) and season - were included. The variable year did not follow a linear pattern, so 


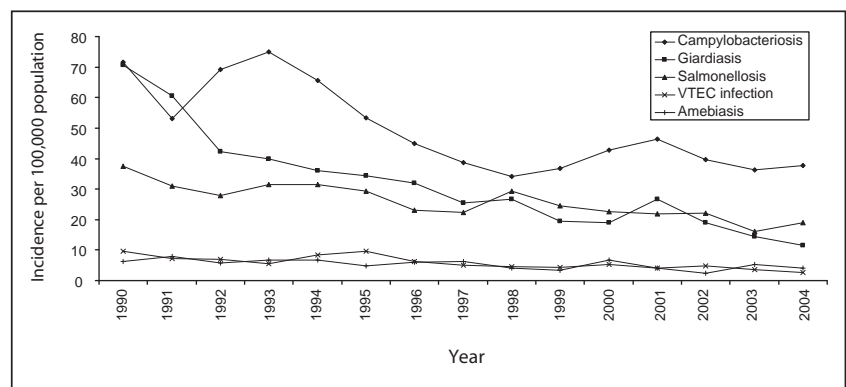

Figure 1) Annual age- and sex-adjusted incidence rates per 100,000 population in Ontario's Waterloo region, 1990 to 2004. VTEC Verotoxigenic Escherichia coli

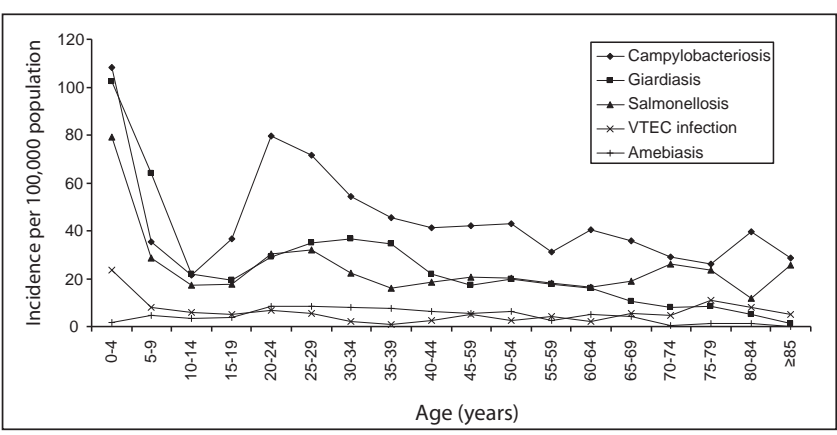

Figure 2) Average age-specific incidence rates per 100,000 population by five-year age categories, in Ontario's Waterloo region, 1990 to 2004. VTEC Verotoxigenic Escherichia coli

TABLE 3

Results of multivariable and univariable negative binomial regression modelling for enteric disease overall $(n=8326)$ in Ontario's Waterloo region, 1990 to 2004

\begin{tabular}{|c|c|c|c|c|c|c|c|}
\hline \multirow[b]{2}{*}{ Variable } & & \multicolumn{3}{|c|}{ Univariable } & \multicolumn{3}{|c|}{ Multivariable } \\
\hline & & IRR & $95 \% \mathrm{Cl}$ & $\mathbf{P}$ & IRR & $95 \% \mathrm{Cl}$ & $\mathbf{P}$ \\
\hline \multirow[t]{2}{*}{ Sex } & Male & Referent & - & - & - & - & - \\
\hline & Female & 0.963 & 0.881-1.051 & 0.398 & 0.969 & $0.922-1.018$ & 0.212 \\
\hline \multirow[t]{3}{*}{ Year* } & 1990-1994 & Referent & - & - & - & - & - \\
\hline & 1995-1999 & 0.667 & $0.613-0.749$ & $<0.001^{\dagger}$ & 0.679 & $0.640-0.720$ & $<0.001^{\dagger}$ \\
\hline & 2000-2004 & 0.549 & $0.496-0.608$ & $<0.001^{\dagger}$ & 0.558 & $0.526-0.593$ & $<0.001^{\dagger}$ \\
\hline \multirow[t]{9}{*}{ Age, years } & $0-4$ & Referent & - & - & - & - & - \\
\hline & $5-9$ & 0.447 & $0.391-0.512$ & $<0.001^{\dagger}$ & 0.447 & $0.405-0.494$ & $<0.001^{\dagger}$ \\
\hline & 10-19 & 0.246 & $0.215-0.281$ & $<0.001^{\dagger}$ & 0.246 & $0.223-0.271$ & $<0.001^{\dagger}$ \\
\hline & $20-29$ & 0.476 & $0.421-0.538$ & $<0.001^{\dagger}$ & 0.475 & $0.438-0.516$ & $<0.001^{\dagger}$ \\
\hline & 30-39 & 0.359 & $0.317-0.407$ & $<0.001^{\dagger}$ & 0.357 & $0.327-0.389$ & $<0.001^{\dagger}$ \\
\hline & $40-49$ & 0.276 & $0.242-0.314$ & $<0.001^{\dagger}$ & 0.280 & $0.255-0.308$ & $<0.001^{\dagger}$ \\
\hline & $50-59$ & 0.255 & $0.222-0.294$ & $<0.001^{\dagger}$ & 0.265 & $0.238-0.294$ & $<0.001^{\dagger}$ \\
\hline & $60-69$ & 0.238 & $0.205-0.277$ & $<0.001^{\dagger}$ & 0.240 & $0.212-0.271$ & $<0.001^{\dagger}$ \\
\hline & $\geq 70$ & 0.208 & $0.178-0.243$ & $<0.001^{\dagger}$ & 0.214 & $0.188-0.243$ & $<0.001^{\dagger}$ \\
\hline \multirow[t]{4}{*}{ Season } & Winter & Referent & - & - & - & - & - \\
\hline & Spring & 1.205 & $1.069-1.360$ & $0.002^{\dagger}$ & 1.199 & $1.113-1.292$ & $<0.001^{\dagger}$ \\
\hline & Summer & 1.881 & $1.674-2.114$ & $<0.001^{\dagger}$ & 1.884 & $1.758-2.020$ & $<0.001^{\dagger}$ \\
\hline & Fall & 1.127 & $0.999-1.272$ & 0.053 & 1.110 & 1.029-1.197 & $0.007^{\dagger}$ \\
\hline
\end{tabular}

*Year was treated as a categorical variable in the model (likelihood ratio $\chi^{2}=391.52, P<0.0001$ ); ${ }^{\dagger}$ Statistically significant at $P \leq 0.05 . \quad$ IRR Incidence rate ratio

it was included as a categorical variable in the model, with three categories (1990 to 1994,1995 to 1999 , and 2000 to 2004). For the regression modelling, the Waterloo region population data were used as the population at risk, and were accessed through the Provincial Health Planning Database, Ontario Ministry of Health and Long-Term Care. Poisson regression models were used to model giardiasis and salmonellosis. Negative binomial regression was used instead of Poisson regression to model enteric illness overall and campylobacteriosis because the overdispersion parameter was significantly different from zero $(\mathrm{P} \leq 0.05)$.

The average annual age- and sex-adjusted incidence rates calculated in the present study were compared with published incidence rates of reportable enteric disease in Ontario. The under-reporting multipliers created by Thomas et al (8) for nationally reported data were adjusted to suit the locally reported data. The adjusted conservative and liberal multipliers were then used to estimate the number of cases of campylobacteriosis, salmonellosis and verotoxigenic Escherichia coli (VTEC) infection in the Waterloo region from 1990 to 2004.

\section{RESULTS}

The dataset contained 8326 cases of 13 reportable enteric illnesses. Campylobacter species, Giardia lamblia and nontyphoidal Salmonella species accounted for over $80 \%$ of reported cases of enteric illness during the 15-year period (Table 1), and a species or serotype was identified in $77.5 \%$ and $50.5 \%$ of the cases of campylobacteriosis and salmonellosis, respectively. The average annual age- and sex-adjusted incidence rates for the 13 enteric illnesses are shown in Table 1; for those enteric illnesses with an average age- and sex-adjusted incidence rate of more than five cases per 100,000 population, rates are shown by year in Figure 1, and average age-specific incidence rates are shown in Figure 2. The overall incidence of enteric illness was lower from 1995 to 1999 and 2000 to 2004 compared with 1990 to 1994 (Table 3). The incidence of enteric illness overall was also lower from 2000 to 2004 compared with 1995 to 1999 (incidence rate ratio $[\operatorname{IRR}]=0.811, \mathrm{P}<0.001$ ). The IRRs for enteric disease overall, campylobacteriosis, giardiasis and salmonellosis are shown in Tables 3, 4, 5 and 6, respectively.

The average seasonal incidence of enteric illness was highest in the summer, with 44.5 cases per 100,000 population. 
TABLE 4

Results of multivariable and univariable negative binomial regression modelling for cases of campylobacteriosis $(n=3152)$, in Waterloo region, Ontario, 1990 to 2004

\begin{tabular}{|c|c|c|c|c|c|c|c|}
\hline \multirow[b]{2}{*}{ Variable } & & \multicolumn{3}{|c|}{ Univariable } & \multicolumn{3}{|c|}{ Multivariable } \\
\hline & & IRR & $95 \% \mathrm{Cl}$ & $\mathbf{P}$ & IRR & $95 \% \mathrm{Cl}$ & $\mathbf{P}$ \\
\hline \multirow[t]{2}{*}{ Sex } & Male & Referent & - & - & - & - & - \\
\hline & Female & 0.905 & $0.814-1.006$ & 0.065 & 0.917 & $0.849-0.990$ & $0.027^{\dagger}$ \\
\hline \multirow{2}{*}{ Year* } & 1995-1999 & 0.634 & $0.560-0.717$ & $<0.001^{\dagger}$ & 0.630 & $0.574-0.692$ & $<0.001^{\dagger}$ \\
\hline & 2000-2004 & 0.626 & $0.554-0.708$ & $<0.001^{\dagger}$ & 0.620 & $0.565-0.680$ & $<0.001^{\dagger}$ \\
\hline \multirow[t]{7}{*}{ Age, years } & $0-4$ & Referent & - & - & - & - & - \\
\hline & 10-19 & 0.271 & $0.223-0.329$ & $<0.001^{\dagger}$ & 0.270 & $0.229-0.317$ & $<0.001^{\dagger}$ \\
\hline & $20-29$ & 0.696 & $0.589-0.822$ & $<0.001^{\dagger}$ & 0.688 & $0.605-0.783$ & $<0.001^{\dagger}$ \\
\hline & 30-39 & 0.466 & $0.392-0.553$ & $<0.001^{\dagger}$ & 0.460 & $0.401-0.527$ & $<0.001^{\dagger}$ \\
\hline & $40-49$ & 0.383 & $0.319-0.459$ & $<0.001^{\dagger}$ & 0.388 & $0.335-0.449$ & $<0.001^{\dagger}$ \\
\hline & $50-59$ & 0.346 & $0.283-0.421$ & $<0.001^{\dagger}$ & 0.355 & $0.300-0.419$ & $<0.001^{\dagger}$ \\
\hline & $60-69$ & 0.353 & $0.285-0.436$ & $<0.001^{\dagger}$ & 0.356 & $0.296-0.428$ & $<0.001^{\dagger}$ \\
\hline \multirow{2}{*}{ Season } & Summer & 2.267 & $1.973-2.604$ & $<0.001^{\dagger}$ & 2.280 & $2.043-2.544$ & $<0.001^{\dagger}$ \\
\hline & Fall & 1.115 & $0.959-1.296$ & 0.156 & 1.109 & $0.980-1.255$ & 0.102 \\
\hline
\end{tabular}

${ }^{*}$ To control for year, it was included as a categorical variable in the model (likelihood ratio $\left.\chi^{2}=161.99, P<0.0001\right)$. Referent was 1990 and was compared with 2004;

${ }^{\dagger}$ Statistically significant at $P \leq 0.05$. IRR Incidence rate ratio

TABLE 5

Results of multivariable and univariable poisson regression modelling for cases of giardiasis $(n=2022)$, in Waterloo region, Ontario, 1990 and 2004

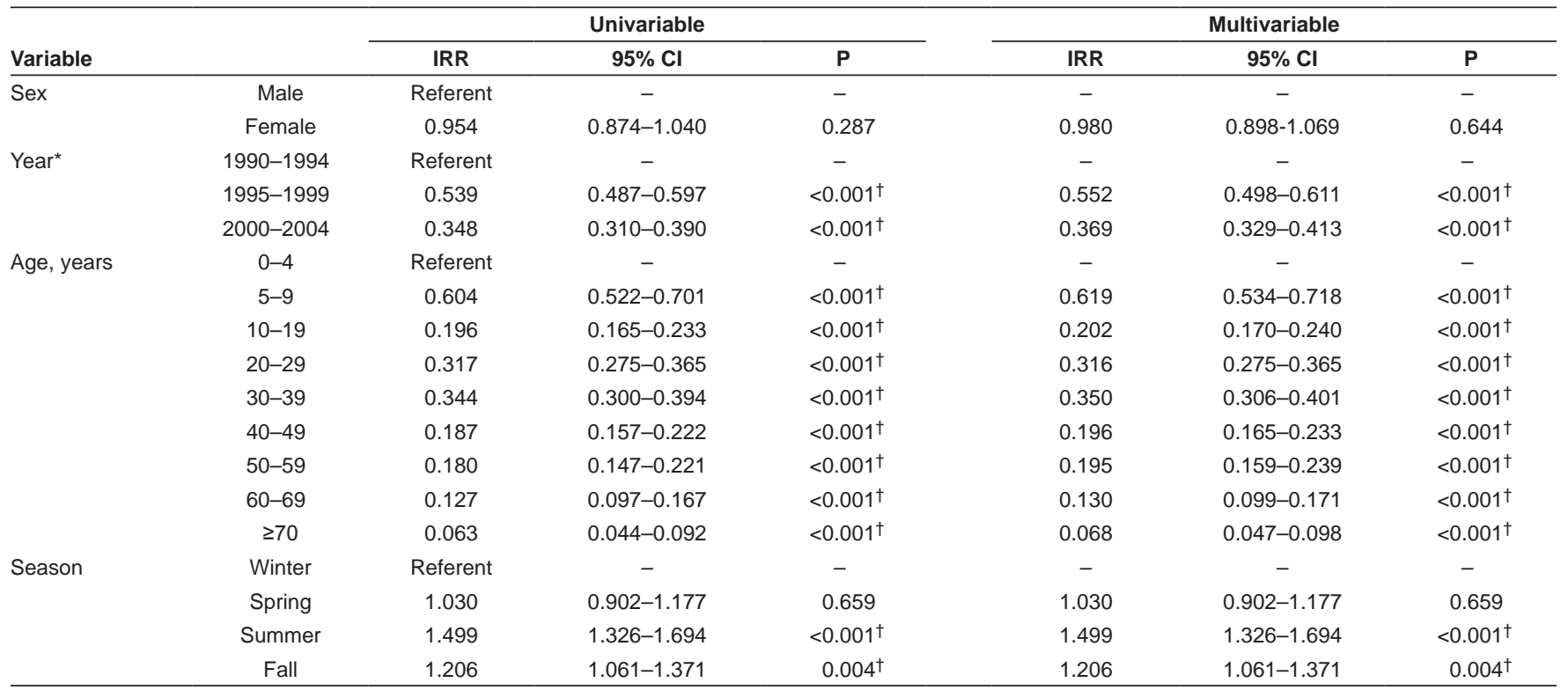

${ }^{*}$ To control for year it was included as a categorical variable in the model (likelihood ratio $\chi^{2}=469.50, P<0.0001$ ); ${ }^{\dagger}$ Statistically significant at $P \leq 0.05$. IRR Incidence rate ratio

Spring, fall and winter had 28.7, 26.4, and 23.8 cases of enteric illnesses per 100,000 population, respectively. The average seasonal incidence rates for each of the 13 enteric illnesses are shown in Table 7. Tables 3, 4, 5 and 6 show the incidence of enteric disease overall, campylobacteriosis, giardiasis and salmonellosis, respectively, by season. For all four, the incidence of disease in the summer was significantly higher compared with the other three seasons $(\mathrm{P} \leq 0.05)$. The incidence of giardiasis was also higher in the fall than in the spring ( $I R R=1.17, P=0.015)$, but this was not the case for enteric disease overall, campylobacteriosis or salmonellosis.

Overall, males and females represented $51.1 \%$ and $48.9 \%$ of cases, respectively. The only statistically significant differences in the incidence rates of females relative to males were in campylobacteriosis (46.8 versus 51.8 per 100,000 population; $\mathrm{P}<0.05)$ and salmonellosis $(27.0$ versus 24.5 per 100,000 population; $\mathrm{P}<0.05$ ). 
TABLE 6

Results of multivariable and univariable poisson regression modelling for cases of nontyphoidal salmonellosis ( $\mathrm{n}=1649$ ), in Waterloo region, Ontario, 1990 to 2004

\begin{tabular}{|c|c|c|c|c|c|c|c|}
\hline \multirow[b]{2}{*}{ Variable } & & \multicolumn{3}{|c|}{ Univariable } & \multicolumn{3}{|c|}{ Multivariable } \\
\hline & & IRR & $95 \% \mathrm{Cl}$ & $\mathbf{P}$ & IRR & $95 \% \mathrm{Cl}$ & $\mathbf{P}$ \\
\hline \multirow[t]{2}{*}{ Sex } & Male & Referent & - & - & - & - & - \\
\hline & Female & 1.104 & $1.002-1.216$ & $0.045^{\dagger}$ & 1.109 & $1.007-1.222$ & $0.036^{\dagger}$ \\
\hline \multirow[t]{3}{*}{ Year* } & 1990-1994 & Referent & - & - & - & - & - \\
\hline & 1995-1999 & 0.794 & $0.708-0.890$ & $<0.001^{\dagger}$ & 0.811 & $0.723-0.909$ & $<0.001^{\dagger}$ \\
\hline & 2000-2004 & 0.624 & $0.554-0.703$ & $<0.001^{\dagger}$ & 0.650 & $0.577-0.733$ & $<0.001^{\dagger}$ \\
\hline \multirow[t]{9}{*}{ Age, years } & $0-4$ & Referent & - & - & - & - & - \\
\hline & $5-9$ & 0.359 & $0.294-0.439$ & $<0.001^{\dagger}$ & 0.363 & $0.297-0.443$ & $<0.001^{\dagger}$ \\
\hline & 10-19 & 0.223 & $0.185-0.269$ & $<0.001^{\dagger}$ & 0.227 & $0.188-0.274$ & $<0.001^{\dagger}$ \\
\hline & $20-29$ & 0.393 & $0.338-0.458$ & $<0.001^{\dagger}$ & 0.394 & $0.338-0.458$ & $<0.001^{\dagger}$ \\
\hline & 30-39 & 0.243 & $0.205-0.288$ & $<0.001^{\dagger}$ & 0.245 & $0.206-0.290$ & $<0.001^{\dagger}$ \\
\hline & $40-49$ & 0.241 & $0.201-0.289$ & $<0.001^{\dagger}$ & 0.246 & $0.205-0.295$ & $<0.001^{\dagger}$ \\
\hline & $50-59$ & 0.239 & $0.194-0.294$ & $<0.001^{\dagger}$ & 0.247 & $0.201-0.304$ & $<0.001^{\dagger}$ \\
\hline & $60-69$ & 0.215 & $0.168-0.275$ & $<0.001^{\dagger}$ & 0.217 & $0.169-0.277$ & $<0.001^{\dagger}$ \\
\hline & $\geq 70$ & 0.284 & $0.228-0.354$ & $<0.001^{\dagger}$ & 0.288 & $0.231-0.359$ & $<0.001^{\dagger}$ \\
\hline \multirow[t]{4}{*}{ Season } & Winter & Referent & - & - & - & - & - \\
\hline & Spring & 1.128 & $0.974-1.307$ & 0.108 & 1.128 & $0.974-1.307$ & 0.108 \\
\hline & Summer & 1.764 & $1.543-2.017$ & $<0.001^{\dagger}$ & 1.764 & $1.543-2.017$ & $<0.001^{\dagger}$ \\
\hline & Fall & 1.030 & $0.886-1.197$ & 0.701 & 1.030 & 0.886-1.197 & 0.701 \\
\hline
\end{tabular}

${ }^{*}$ To control for year, it was included as a categorical variable in the model (likelihood ratio $\left.\chi^{2}=71.06, P<0.0001\right) ;{ }^{\dagger}$ Statistically significant at P $\leq 0.05 . \quad$ IRR Incidence rate ratio

TABLE 7

Average seasonal incidence rates per 100,000 population (by season) of 13 reportable enteric illnesses in Waterloo region, Ontario, 1990 to 2004

\begin{tabular}{lcccc}
\hline & \multicolumn{4}{l}{ Season* } \\
\cline { 2 - 5 } Disease & Summer & Fall & Winter & Spring \\
\hline Campylobacteriosis & 18.39 & 8.96 & 8.07 & 11.50 \\
Giardiasis & 9.54 & 7.67 & 6.40 & 6.58 \\
Nontyphoidal salmonellosis & 8.80 & 5.16 & 4.98 & 5.66 \\
VTEC infection & 2.67 & 0.99 & 0.59 & 1.32 \\
Amebiasis & 1.48 & 1.23 & 1.14 & 1.30 \\
Cryptosporidiosis & 0.99 & 0.40 & 0.16 & 0.19 \\
Yersiniosis & 0.89 & 0.65 & 0.84 & 0.62 \\
Shigellosis & 0.84 & 0.46 & 0.71 & 0.59 \\
Hepatitis A infection & 0.83 & 0.70 & 0.61 & 0.56 \\
Listeriosis & 0.07 & 0.03 & 0.04 & 0.03 \\
Cyclosporiasis & 0.01 & 0.06 & 0.01 & 0.06 \\
Typhoid fever & 0.01 & 0.03 & 0.16 & 0.19 \\
Paratyphoid fever & 0.00 & 0.01 & 0.06 & 0.06 \\
\hline *Summer (July to September), Fall (October to December), Winter (January to \\
March) and Spring (April to June). VTEC Verotoxigenic Escherichia coli
\end{tabular}

Overall, the age of cases ranged from younger than one year to 100 years, with a mean of 27.5 years and a median of 26 years. Children younger than five years of age and adults 60 years of age and older represented $19.0 \%$ and $8.5 \%$ of cases, respectively, while adults 20 to 29 years of age represented $20.4 \%$ of cases. The highest rate of enteric illness occurred in children zero to four years of age (23.8 cases per 100,000 population) followed by adults 20 to 24 years of age ( 11.3 cases per $100,000)$ and 25 to 29 years of age $(11.1$ cases per 100,000$)$. The incidence of enteric illness in those zero to four years of age was significantly higher than any other age category $(\mathrm{P} \leq 0.05)$ for enteric illness overall, campylobacteriosis, giardiasis and salmonellosis (Tables 3 to 6). For enteric disease overall, campylobacteriosis and salmonellosis, the incidence was significantly higher in those 20 to 29 years of age than in those 10 to 19 years of age $(\mathrm{IRR}=1.92, \mathrm{P}<0.0001 ; \mathrm{IRR}=2.54, \mathrm{P}<0.0001$; $\mathrm{IRR}=1.73, \mathrm{P}<0.0001$, respectively) and those 30 to 39 years of age $(\mathrm{IRR}=1.33, \mathrm{P}<0.0001 ; \mathrm{IRR}=1.50, \mathrm{P}<0.0001 ; \mathrm{IRR}=1.61$, $\mathrm{P}<0.0001$, respectively) with the same illnesses (Tables $3,4,6$ ). The incidence of giardiasis was significantly higher in those 20 to 29 years of age than in those 10 to 19 years of age (IRR $=1.55$, $\mathrm{P}<0.0001$ ), but lower (although not significantly) than the incidence in those 30 to 39 years of age (IRR $=0.90, P=0.146$ [Table 5]).

The highest proportions of asymptomatic infections were reported for amebiasis $(16.7 \%)$, giardiasis $(11.73 \%)$ and paratyphoid fever $(11.1 \%)$. Depending on the pathogen, fever was reported in 3.5\% (giardiasis) to $77.8 \%$ (paratyphoid fever) of cases. Bloody diarrhea was reported by $65.7 \%$ of VTEC infection cases, $20.2 \%$ of campylobacteriosis cases, $19.9 \%$ of shigellosis cases and in less than $13.0 \%$ of cases of all other diseases. Hemolytic uremic syndrome was reported in $1.1 \%$ of cases of VTEC infection, and was not a sequela of any other reported illness. All cases of hemolytic uremic syndrome were in children younger than five years of age. Jaundice was the most frequently reported sign in cases of hepatitis A infection $(52.2 \%)$, but was also reported infrequently ( $0.5 \%$ or lower) in cases of VTEC infection, amebiasis, salmonellosis and campylobacteriosis.

The percentage of cases associated with outbreaks are shown by illness, along with the inpatient hospitalization and case-fatality rates (Table 8 ). Overall, $11.7 \%$ of patients were hospitalized during their illness, with $73.8 \%$ admitted as inpatients and $26.2 \%$ treated as outpatients. Twenty-five deaths were reported. Listeriosis was the underlying cause in two of the deaths, and contributed to one death; all patients were 65 years of age or older. In six deaths, enteric illness was determined to be an incidental finding not contributing to 


\begin{tabular}{|c|c|c|c|c|c|c|c|c|c|}
\hline \multirow[b]{3}{*}{ Disease } & \multirow{3}{*}{$\begin{array}{l}\% \\
O A\end{array}$} & \multicolumn{4}{|c|}{$\begin{array}{c}\text { Inpatient } \\
\text { hospitalization rate }\end{array}$} & \multicolumn{4}{|c|}{ Case-fatality rate } \\
\hline & & \multirow[b]{2}{*}{ Overall } & \multirow{2}{*}{$\begin{array}{l}0-4 \\
\text { yrs }\end{array}$} & \multirow{2}{*}{$\begin{array}{c}5-49 \\
\text { yrs }\end{array}$} & \multirow{2}{*}{$\begin{array}{l}\geq 50 \\
\text { yrs }\end{array}$} & \multicolumn{4}{|c|}{$0-4 \quad 5-49 \geq 50$} \\
\hline & & & & & & Overall & yrs & yrs & yrs \\
\hline Listeriosis & 0.0 & 100.0 & - & 100.0 & 100.0 & 41.7 & - & 0.0 & 45.5 \\
\hline $\begin{array}{l}\text { Paratyphoid } \\
\text { fever }\end{array}$ & 0.0 & 44.4 & - & 42.9 & 100.0 & 0.0 & - & 0.0 & 0.0 \\
\hline VTEC infection & 2.4 & 38.8 & - & 38.1 & 53.0 & 0.5 & 0.0 & 0.0 & 3.0 \\
\hline Typhoid fever & 0.0 & 37.0 & 0.0 & 47.6 & - & 0.0 & 0.0 & 0.0 & - \\
\hline $\begin{array}{l}\text { Hepatitis A } \\
\text { infection }\end{array}$ & 17.6 & 17.0 & 0.0 & 14.3 & 47.8 & 0.0 & 0.0 & 0.0 & 0.0 \\
\hline Shigellosis & 1.1 & 14.2 & 42.9 & 10.2 & 10.7 & 0.0 & 0.0 & 0.0 & 0.0 \\
\hline $\begin{array}{l}\text { Nontyphoidal } \\
\text { salmonellosis }\end{array}$ & 3.0 & 12.2 & 15.6 & 7.8 & 23.0 & 0.5 & 0.0 & 0.2 & 2.0 \\
\hline Cyclosporiasis & 0.0 & 10.0 & 100.0 & 0.0 & 0.0 & 0.0 & 0.0 & 0.0 & 0.0 \\
\hline Campylobacteriosis & 0.2 & 6.9 & 7.2 & 5.6 & 11.4 & 0.1 & 0.2 & 0.0 & 0.0 \\
\hline Yersiniosis & 0.5 & 6.9 & 5.6 & 5.4 & 15.8 & 0.5 & 0.0 & 0.0 & 5.3 \\
\hline Cryptosporidiosis & 0.0 & 5.9 & 10.3 & 4.1 & 0.0 & 0.0 & 0.0 & 0.0 & 0.0 \\
\hline Giardiasis & 1.0 & 2.2 & 3.9 & 1.3 & 4.4 & 0.3 & 0.0 & 0.1 & 1.9 \\
\hline Amebiasis & 0.0 & 2.0 & 0.0 & 1.1 & 7.3 & 0.3 & 0.0 & 0.0 & 1.8 \\
\hline
\end{tabular}

OA Outbreak associated; VTEC Verotoxigenic Escherichia coli; Yrs Years

death. The remaining 16 deaths did not have documented causes; this included a 25- to 29-year-old patient with salmonellosis. In addition to the 25 deaths, campylobacteriosis was documented as contributing to the cause of death in two patients 15 to 30 years of age; however, the 'deceased' field was not completed for these two patients, and it is unknown whether campylobacteriosis contributed to the death (ie, there were 27 deaths instead of 25) or if the cause of death was entered erroneously.

Overall, food was considered to be the likely probable source in $57.4 \%$ of the cases for which a probable source was reported. Water and person-to-person contact were believed to account for $19.8 \%$ and $19.7 \%$ of cases for which a source was reported, respectively. For cases with an identified risk setting, home $(41.7 \%)$ and travel $(37.0 \%)$ were the most frequently reported settings.

Patients residing in urban areas represented $87.4 \%$ of patients; $12.3 \%$ of patients resided in rural areas and $0.3 \%$ listed residences outside of the Waterloo region. Patients listing residences outside of the Waterloo region represented students with permanent addresses outside of the region, visitors who spent their incubation period in the region (where the likely source of infection was determined to be within the Waterloo region) or cases linked to outbreaks within the region. The proportion of urban cases was higher than expected for amebiasis $(\mathrm{OR}=2.27, \mathrm{P}=0.0002)$ and shigellosis $(\mathrm{OR}=2.39$, $\mathrm{P}=0.0006$ ). The proportion of rural cases was higher than expected for campylobacteriosis $(\mathrm{OR}=1.15, \mathrm{P}=0.0091)$, hepatitis A infection $(\mathrm{OR}=2.38, \mathrm{P}<0.0001)$, yersiniosis $(\mathrm{OR}=1.64$, $\mathrm{P}=0.0141)$, VTEC infection $(\mathrm{OR}=1.43, \mathrm{P}=0.0165)$ and cryptosporidiosis $(\mathrm{OR}=2.50, \mathrm{P}=0.0001)$.

Although information on travel outside of Canada was documented for just $1 \%$ of all enteric illness cases, it was reported for $21 \%$ of the cases of hepatitis $\mathrm{A}$ infection, and for at least $70 \%$ of the cases of cyclosporiasis (70\%), typhoid fever (74\%) and paratyphoid fever (78\%). Travel was also reported for less than $2 \%$ of the cases of amebiasis, shigellosis, giardiasis and campylobacteriosis.

Published provincial incidence rates were available for comparing nine of the 13 enteric illnesses (Table 9). Provincial incidence rates for salmonellosis, giardiasis and campylobacteriosis were lower than the rates observed in the present study, while the provincial rate of VTEC infection was marginally lower than the rate observed in the study. Provincial incidence rates of yersiniosis, shigellosis, cryptosporidiosis and hepatitis $\mathrm{A}$ infection were similar to the rates observed in the present study, while the rate of listeriosis observed in the study was lower than the provincial rate.

After adjusting for under-reporting using the estimates from Thomas et al (8), the 5203 reported cases of campylobacteriosis, salmonellosis and VTEC infection combined (representing $62.5 \%$ of enteric disease) in the Waterloo region from 1990 to 2004 were estimated to represent between 95,100 and 226,700 community cases, or between 6340 and 15,115 community cases annually.

\section{DISCUSSION}

From 1990 to 2004, 8326 cases of enteric disease were reported in the Waterloo region. Each of the 13 enteric diseases investigated had unique epidemiological characteristics; however, the overall trends of enteric illness were heavily influenced by campylobacteriosis, giardiasis and nontyphoidal salmonellosis, which represented over $80 \%$ of the total cases during the study period.

As expected, the incidence of enteric disease overall, campylobacteriosis, giardiasis and salmonellosis were significantly higher in the summer than any other season. This increase may be due to an increase in outdoor activities, social gatherings incorporating food including potlucks and picnics, recreational use of water or travel. There is also evidence that flies can function as mechanical vectors, depositing bacteria $(24,25)$ and protozoa $(26,27)$ on food, which is likely related to the seasonality of foodborne illnesses. For diseases with fewer than 500 cases, the following qualitative differences were noted. Paratyphoid and typhoid fevers were more frequently reported in the winter and spring; this is likely due to winter travel to endemic regions, such as India (28). The incidence of cyclosporiasis in the Waterloo region was highest in the spring and fall. Historically, outbreaks of cyclosporiasis have been associated with Guatemalan raspberries (29); however, these peaks could be associated with other seasonal food products or travel outside of Canada, which was reported by seven of the 10 cases of cyclosporiasis.

The incidence of enteric disease overall did not differ significantly by sex. However, the incidence of campylobacteriosis was significantly higher in males, and the incidence of salmonellosis was significantly higher in females. The higher incidence of campylobacteriosis in males observed could be related to poor food handling practices (30). The higher rates of salmonellosis in females could possibly be associated with caring for stoolincontinent infants or children with salmonellosis, or to higher consumption of fresh fruits and vegetables - a trend that has been recently observed in the Waterloo region (31). For diseases 
TABLE 9

A comparison of study designs, and incidence rates of enteric disease, between the present study and published studies using reportable disease data, in Ontario

\begin{tabular}{|c|c|c|c|c|c|c|}
\hline Illness & Study location & Study period & Type of data & Type of rates & Annual incidence rate (per 100,000$)$ & Reference \\
\hline \multirow[t]{3}{*}{ Campylobacteriosis } & Waterloo & 1990-2004 & All cases & Age- and sex-adjusted & 49.69 & Present study \\
\hline & Ontario & 1997-2001 & Sporadic & Age- and sex-adjusted & 42.3 & 12 \\
\hline & Ontario & 2002 & Travel removed & Average of sex-specific & 34.7 & 16 \\
\hline \multirow[t]{2}{*}{ Giardiasis } & Waterloo & 1990-2004 & All cases & Age- and sex-adjusted & 31.89 & Present study \\
\hline & Ontario & 1990-1998 & All cases & Age- and sex-adjusted & 25.77 & 13 \\
\hline \multirow[t]{3}{*}{ Salmonellosis } & Waterloo & 1990-2002 & All cases & Age- and sex-adjusted & 25.97 & Present study \\
\hline & Ontario & 1997-2002 & Sporadic & Age- and sex-adjusted & 22.6 & 12 \\
\hline & Ontario & 2002 & Travel removed & Average of sex-specific & 17.3 & 16 \\
\hline \multirow[t]{4}{*}{ VTEC infection } & Waterloo & 1990-2004 & All cases & Age- and sex-adjusted & 5.86 & Present study \\
\hline & Ontario & 1990-1994 & All cases & Age- and sex-adjusted & 4.8 & 15 \\
\hline & Ontario & 1997-2003 & Sporadic & Age- and sex-adjusted & 3.7 & 12 \\
\hline & Ontario & 2002 & Travel removed & Average of sex-specific & 3.2 & 16 \\
\hline \multirow[t]{3}{*}{ Yersiniosis } & Ontario & 1990-2004 & All cases & Age- and sex-adjusted & 3.11 & Present study \\
\hline & Ontario & 2002 & Travel removed & Average of sex-specific & 3.2 & 16 \\
\hline & Ontario & 1997-2004 & Sporadic & Age- and sex-adjusted & 3.0 & 12 \\
\hline \multirow[t]{3}{*}{ Shigellosis } & Waterloo & 1990-2002 & All cases & Age- and sex-adjusted & 2.83 & Present study \\
\hline & Ontario & 2002 & Travel removed & Average of sex-specific & $6.2^{*}$ & 16 \\
\hline & Ontario & 1997-2005 & Sporadic & Age- and sex-adjusted & 2.7 & 12 \\
\hline \multirow[t]{3}{*}{ Hepatitis A infection } & Waterloo & 1990-2004 & All cases & Age- and sex-adjusted & 2.72 & Present study \\
\hline & Ontario & 1997-2006 & Sporadic & Age- and sex-adjusted & 2.3 & 12 \\
\hline & Ontario & 2002 & Travel removed & Average of sex-specific & 0.6 & 16 \\
\hline \multirow[t]{2}{*}{ Cryptosporidiosis } & Waterloo & 1990-2004 & All cases & Age and sex-adjusted & 2.98 & Present study \\
\hline & Ontario & 1996-1997 & Endemic & Age- and sex-adjusted & 2.13 & 14 \\
\hline \multirow[t]{3}{*}{ Listeriosis } & Waterloo & 1990-2003 & All cases & Age- and sex-adjusted & 0.19 & Present study \\
\hline & Ontario & 2002 & Travel removed & Average of sex-specific & 0.4 & 16 \\
\hline & Ontario & 1997-2007 & Sporadic & Age- and sex-adjusted & 0.3 & 12 \\
\hline
\end{tabular}

*Includes an outbreak

with fewer than 500 cases, qualitative differences among the sexes were noted that were consistent with previous studies. For instance, the higher rate of amebiasis observed in males may be due to sexual activity in homosexual males, who are an identified risk group for amebiasis (32). Higher rates of shigellosis and VTEC infection were observed in females, consistent with provincial rates from 1997 to 2001 (12), but the exact reasons for these sex differences are unknown.

The overall age distribution of enteric illness in the Waterloo region was driven by the age distributions of campylobacteriosis, salmonellosis and giardiasis, and was consistent with age distributions for enteric illness identified provincially (12). The age distribution for giardiasis was slightly different from campylobacteriosis and salmonellosis because the incidence in those 20 to 29 years of age was not significantly different from those 30 to 39 years of age, which is consistent with the age distribution of giardiasis in Ontario from 1990 to 1998 (13).

For enteric illness overall, the most frequently reported symptom was diarrhea ( $85.4 \%$ of cases). This is important in light of the recent use of syndromic surveillance of antidiarrheal drug sales to monitor community health. Syndromic surveillance of antidiarrheal and antinauseant drug sales have been used retrospectively to attempt to identify waterborne outbreaks of Cryptosporidium, E coli O157:H7 and Campylobacter (17). In the Waterloo region, such surveillance of antidiarrheal and antinauseant drugs would be particularly suited to monitoring illnesses such as shigellosis, salmonellosis, yersiniosis, cyclosporiasis or giardiasis, because $55.1 \%$ to $80.7 \%$ of the cases reported diarrhea, and an additional $13.8 \%$ to $27.5 \%$ experienced nausea or vomiting.

Of the 13 illnesses, listeriosis had the highest inpatient hospitalization and case-fatality rates. Although inpatient hospitalization and case-fatality rates were lower for campylobacteriosis, salmonellosis and VTEC infection, these three illnesses combined represented $78.7 \%$ of the total hospitalizations for enteric disease during the study period. Thus, despite the fact that disease-specific hospitalization and case-fatality rates were relatively low, the associated burden in the Waterloo region due to campylobacteriosis, salmonellosis and VTEC infection was substantially greater than listeriosis.

For enteric illness overall in the Waterloo region, the most frequently reported probable source was food $(57.3 \%)$, followed by water (19.8\%) and person-to-person contact (19.7\%). Lee and Middleton (12) also found food to be the most probable source of enteric disease (74.0\%) in Ontario from 1997 to 2001 , followed by water $(7.0 \%)$ and person-to-person contact (6.0\%). However, Lee and Middleton (12) investigated eight enteric pathogens, excluding amebiasis, giardiasis and cryptosporidiosis, for which the probable source in the Waterloo region was most frequently identified to be water, likely explaining the higher proportion of enteric illness attributed to water in Waterloo.

For enteric illness overall in the Waterloo region, home $(41.7 \%)$ and travel $(36.9 \%)$ were the two most frequently identified risk settings, compared with $50.2 \%$ and $24.6 \%$, respectively, for Ontario from 1997 to 2001 (12). For cases of campylobacteriosis, salmonellosis and shigellosis, travel was 
more frequently identified as the risk setting in the Waterloo region than provincially, and was also identified more frequently as the risk setting for cases of cryptosporidiosis and giardiasis in the Waterloo region compared with historically reported provincial data $(13,14)$. Information on risk setting was missing or unspecified for nearly one-half $(49.1 \%)$ of the cases; therefore, bias associated with missing data could have had a large impact on these comparisons. Furthermore, because the probable source of infection and risk setting are determined by a public health investigator based on an interview with the patient, they may reflect what is already known about a particular illness rather than supporting the identification of previously unknown risk settings or sources of a particular infection. Public health units can mitigate this by systematically collecting a broad spectrum of possible exposures. Surveillance programs, such as C-EnterNet, can contribute to the creation and use of such standardized collection tools.

Cases of amebiasis and shigellosis living in urban areas of the Waterloo region represented a larger proportion of cases than expected, based on the population distribution. Immigrants and refugees from developing countries are often carriers of amebiasis (33); $98 \%$ of recent immigrants to the Waterloo region settle in urban areas (34). Thus, a higher proportion of immigrants settling in the urban Waterloo region could explain the higher proportion of amebiasis observed in the urban areas. Higher rates of shigellosis in urban areas have also been reported in other parts of Canada, including Alberta (35). The specific reason for this is unknown, but is likely related to transmission dynamics. Given that humans are the main reservoir for Shigella species, the lower population density in rural areas may result in fewer person-to-person contacts and less contact with potentially contaminated fomites, compared with urban areas.

Patients with campylobacteriosis, VTEC infection, cryptosporidiosis, yersiniosis and hepatitis $\mathrm{A}$ infection who are living in rural areas of the Waterloo region represented a larger proportion of cases than expected, based on the population distribution of the region. Campylobacteriosis, VTEC infection, cryptosporidiosis and yersiniosis are zoonotic diseases, and increased rates of campylobacteriosis in rural areas have been associated with contact with live farm animals, particularly poultry (36). Additionally, Campylobacter species, E coli and Cryptosporidium species are common contaminants of rural water sources (37), including wells and cisterns, which rural residents of the region rely on. Thus, it is possible that higher rates of campylobacteriosis, VTEC infection, cryptosporidiosis and yersiniosis observed in rural Waterloo region are due to exposure to rural risks, such as farm animals and rural drinking water. Rural Waterloo region is home to a socially contained religious community, where outbreaks of hepatitis A virus occurred in 1991 (38) and 1997 (21).

\section{REFERENCES}

1. Wheeler JG, Sethi D, Cowden JM, et al. Study of infectious intestinal disease in England: Rates in the community, presenting to general practice, and reported to national surveillance. BMJ 1999;318:1046-50.

2. Mead PS, Slutsker L, Dietz V, et al. Food-related illness and death in the United States. Emerg Infect Dis 1999;5:607-25.

3. Scallan E, Majowicz SE, Hall G, et al. Prevalence of diarrhoea in the community in Australia, Canada, Ireland, and the United States. Int J Epidemiol 2005;34:454-60.
This may explain the larger proportion of rural cases of hepatitis A infection observed during the study period.

Travel outside of Canada was reported by at least $70 \%$ of cases of cyclosporiasis, typhoid fever, paratyphoid fever, and to a lesser extent in cases with hepatitis A infection (21\%). Although some of these cases may have been contracted during travel outside of Canada, it is important to note that $99 \%$ of the data were missing for the travel variable. Consequently, these results should be interpreted with extreme caution. This underscores the need to collect complete case histories and to structure surveillance databases so that negative answers (ie, travel outside of Canada did not occur) can be provided.

The average annual incidence rates calculated in the present study were higher than most published provincial rates. This difference is not unexpected because our study included all cases, while other studies have removed cases associated with outbreaks $(12,14)$ or travel $(16)$. In addition, because the incidence of disease declined throughout the study period from 1990 to 2004, published rates that did not include the early to mid-1990s would likely be lower than those reported here.

Under-reporting is a problem in reportable disease data (1-3,8-16), and the rates calculated for the present study are based on reported cases. Recent work (8) at the national level estimated the number of community cases of salmonellosis, campylobacteriosis and VTEC infection that can be expected per case reported nationally. Using these figures, we adjusted the rates of reported illness calculated, which serves to highlight the significant burden of these diseases in the Waterloo region.

Enteric disease is a significant issue in the Waterloo region, with the epidemiology of illness dependent on the pathogen. Overall, rates of enteric illness appeared to be declining, although whether this is a true decrease or a reporting artifact is unclear. Future studies are needed to calculate under-reporting ratios specific to the Waterloo region. There is also an opportunity to compare future temporal trends to those reported here, to investigate the effect of seasonal changes, demographic changes and changes in the urban and rural distribution of residents on the burden of enteric disease. These results provide a baseline for surveillance efforts, such as C-EnterNet, giving context to future results arising from this initiative.

ACKNOWLEDGEMENTS: The authors thank the Public Health Agency of Canada's C-EnterNet team for input into the initial analysis plan, in particular Dr Frank Pollari, who also provided critical review of manuscript drafts; the Region of Waterloo Public Health Department for providing the data; Brenda Miller (Region of Waterloo Public Health) for describing reportable disease data collection processes; and the Public Health Agency of Canada for funding the study.
4. Kaferstein FK, Motarjemi Y, Bettcher DW. Foodborne disease control: A transnational challenge. Emerg Infect Dis 1997;3:503-10.

5. Coker AO, Isokpehi RD, Thomas BN, Amisu KO, Obi CL. Human campylobacteriosis in developing countries. Emerg Infect Dis 2002;8:237-43.

6. Kotloff KL, Winickoff JP, Ivanoff B, et al. Global burden of Shigella infections: Implications for vaccine development and implementation of control strategies. Bull World Health Organ 1999;77:651-66. 
7. Crump JA, Youssef FG, Luby SP, et al. Estimating the incidence of typhoid fever and other febrile illnesses in developing countries. Emerg Infect Dis 2003;9:539-44.

8. Thomas MK, Majowicz SE, Sockett PN, et al. Estimated numbers of community cases of illness due to Salmonella, Campylobacter and verotoxigenic Escherichia coli. Can J Infect Dis 2006;17:229-34.

9. Majowicz SE, Edge VL, Fazil A, et al. Estimating the under-reporting rate for infectious gastrointestinal illness in Ontario. Can J Public Health 2005;96:178-81.

10. Flint JA, Dore K, Majowicz SE, Edge VL, Sockett P. From stool to statistics: Reporting of acute gastrointestinal illnesses in Canada. Can J Public Health 2004;95:309-13.

11. Majowicz SE, Dore K, Flint J, et al. Magnitude and distribution of acute, self-reported gastrointestinal illness in a Canadian community. Epidemiol Infect 2004;132:607-17.

12. Lee M, Middleton D. Enteric illness in Ontario, Canada, from 1997 to 2001. J Food Prot 2003;66:953-61.

13. Grieg JD, Michel P, Wilson JB, et al. A descriptive analysis of Giardiasis cases reported in Ontario, 1990-1998. Can J Public Health 2001;92:361-5.

14. Majowicz SE, Michel P, Aramini JJ, McEwen SA, Wilson JB. Descriptive analysis of endemic cryptosporidiosis cases reported in Ontario, 1996-1997. Can J Public Health 2001;92:62-6.

15. Michel, P, Wilson JB, Martin SW, Clarke RC, McEwen SA, Gyles CL. A descriptive study of verocytotoxigenic Escherichia coli (VTEC) cases reported in Ontario, 1990-1994. Can J Public Health 1998:89:253-7.

16. Rajda Z. Descriptive epidemiology of enteric disease in Ontario, 2002. PHERO 2004;15:123-6.

17. Edge VL, Pollari F, Lim G, et al. Syndromic surveillance of gastrointestinal illness using pharmacy over-the-counter sales: A retrospective study of waterborne outbreaks in Saskatchewan and Ontario. Can J Public Health 2004;95:446-50.

18. Rolland E, Moore KM, Robinson VA, McGuinness D. Using Ontario's "Telehealth" health telephone helpline as an early-warning system: A study protocol. BMC Health Services Research 2006;6:10.

19. Laupland KB, Church DL. Population-based laboratory surveillance for Giardia sp and Cryptosporidium sp infections in a large Canadian health region. BMC Infectious Diseases 2005;5:72.

20. Public Health Agency of Canada. Restaurant foodhandler-associated outbreak of Salmonella Heidelberg gastroenteritis by calls to a local telehealth service, Edmonton, Alberta, 2004. Can Commun Dis Rep 2005;31:105-10.

21. Hockin J, Isaacs S, Kittle D, Brimmer G, Bailey N, Tamblyn S. Hepatitis A outbreak in a socially-contained religious community in rural southern Ontario. Can Commun Dis Rep 1997;23:161-6.

22. Doherty JA. Final report and recommendations from the National Notifiable Diseases Working Group. Can Commun Dis Rep 2006;211-25.
23. Dohoo I, Martin W, Stryhn H. Veterinary Epidemiologic Research. Charlottetown: AVC Inc, 2003:80-1.

24. Nichols GL. Fly transmission of Campylobacter. Emerg Infect Dis 2005;11:361-4.

25. Ekdahl K, Normann B, Andersson Y. Could flies explain the elusive epidemiology of campylobacteriosis? BMC Infect Dis 2005;5:11.

26. Graczyk TK, Cranfield MR, Fayer R, Bixler H. House flies (Musca domestica) as transport hosts of Cryptosporidium parvum. Am J Trop Med Hyg 1999;61:500-4.

27. Szostakowska B, Kruminis-Lozowska W, Racewicz M, et al. Cryptosporidium parvum and Giardia lamblia recovered from flies on a cattle farm and in a landfill. Appl Environ Microbiol 2004;70:3742-4.

28. Ekdahl K, de Jong B, Anderson Y. Risk of travel-associated typhoid and paratyphoid fevers in various regions. J Travel Med 2005;12:197-204.

29. Herwaldt BL, Beach MJ; the Cyclospora Working Group. The return of Cyclospora in 1997: Another outbreak of cyclosporiasis in North America associated with imported raspberries. Ann Intern Med 1999;130:210-20.

30. Rajda Z. Descriptive epidemiology of Campylobacter enteritis reported in Ontario, 2003. PHERO 2004;15:166-78.

31. Nesbitt A, Majowicz S, Finley R, et al. Food consumption patterns in the Waterloo Region, Ontario, Canada: A cross-sectional telephone survey. BMC Public Health 2008;24:8:370.

32. Markell EK, Havens RF, Kuritsubo RA. Intestinal parasitic infections in homosexual men at a San Francisco health fair. West J Med 1983;139:177-8.

33. Lifson AR, Thai D, O'Fallon A, Mills WA, Hang K. Prevalence of tuberculosis, hepatitis $\mathrm{B}$ virus, and intestinal parasitic infections among refugees to Minnesota. Public Health Reports 2002;117:69-77.

34. Region of Waterloo. Region of Waterloo Statistical Profile: Populations and Households. <http://www.region.waterloo.on.ca/web/ region.nsf/c56e308f49bfeb7885256 abc0071ec9a/9E792B1747B50842 85256B0E006777AD/\$file/Pop_Lang. PDF?openelement> (Version current at October 11, 2006).

35. Alberta Health and Wellness. Public health notifiable disease management guidelines: Shigellosis. $<$ http://www.health.gov.ab.ca/ professionals/ND_Shigellosis.pdf> (Version current at October 28, 2006).

36. Potter RC, Kaneene JB, Hall WN. Risk factors for sporadic Campylobacter jejuni infections in rural Michigan: A prospective case-control study. Am J Public Health 2003;93:2118-23.

37. Weir E. Well-Water maintenance. CMAJ 2005;172:1438.

38. Bell BP, Snider N, Bailey NA, Egan C. Hepatitis A outbreak: Waterloo Region. PHERO 1992;3:380-3. 


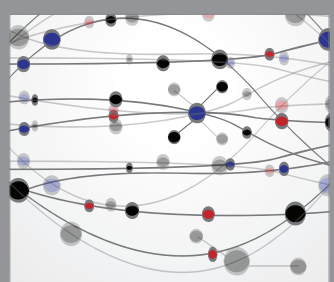

The Scientific World Journal
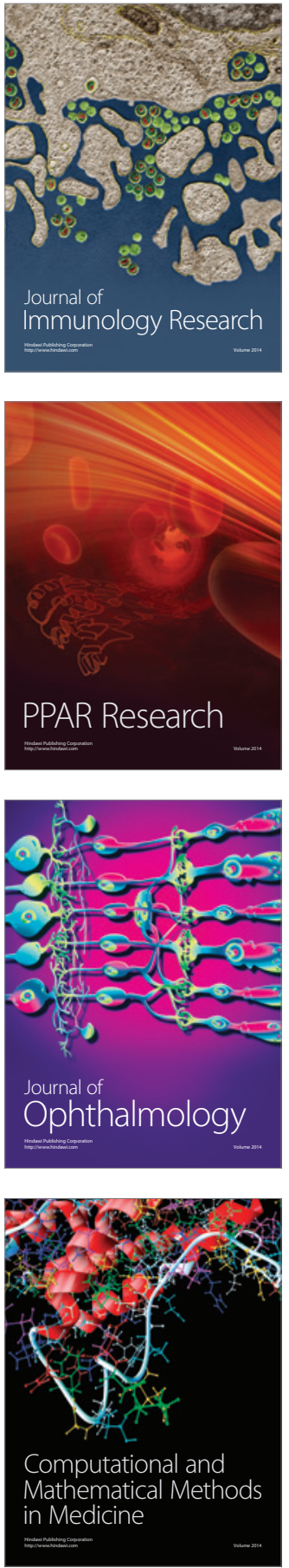

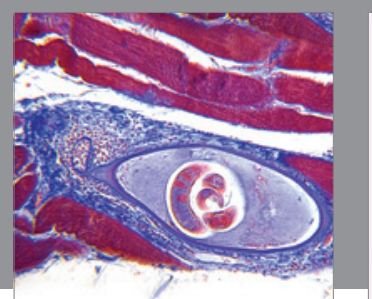

Gastroenterology Research and Practice

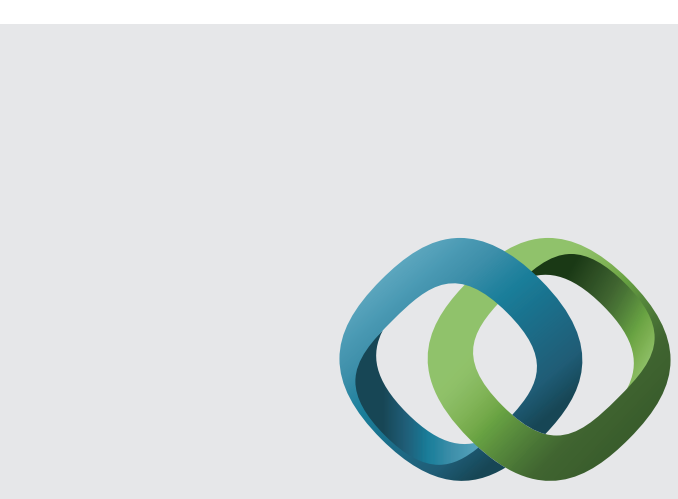

\section{Hindawi}

Submit your manuscripts at

http://www.hindawi.com
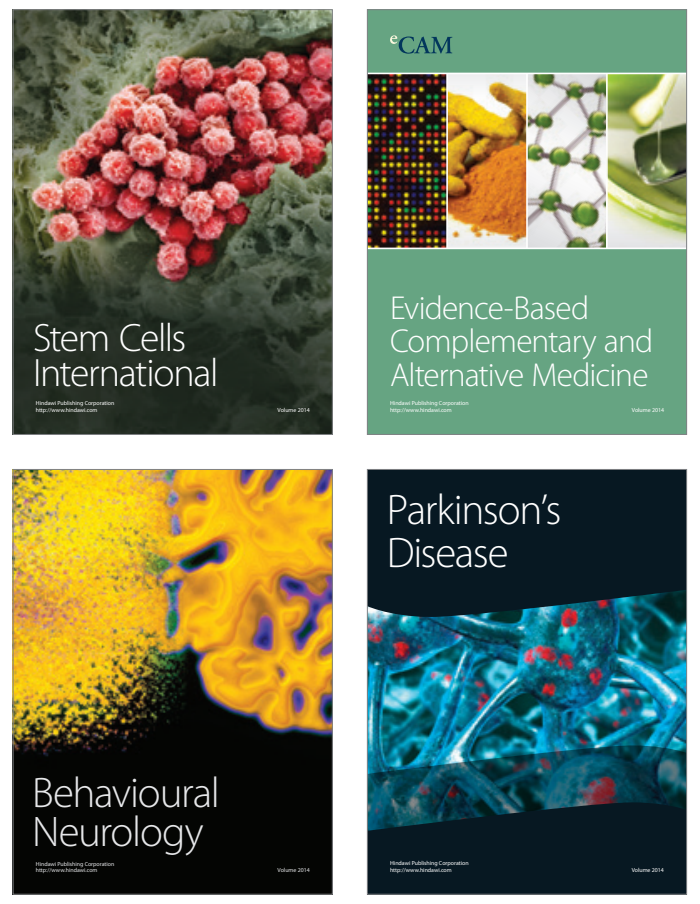
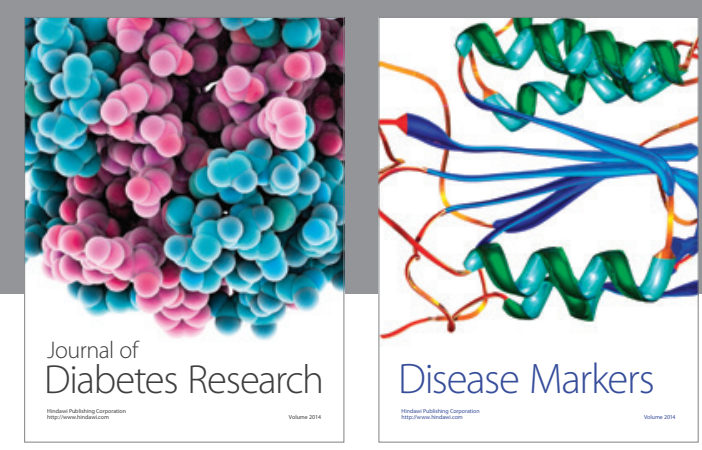

Disease Markers
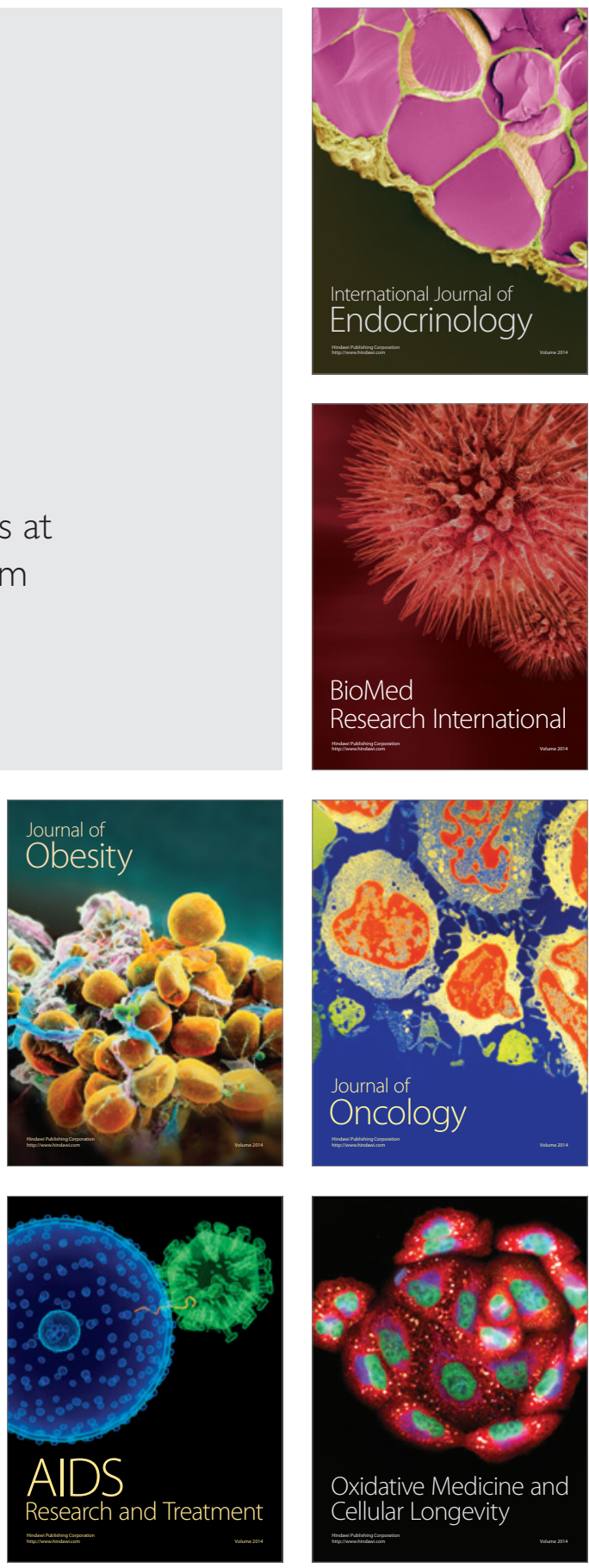